\title{
GIẢI PHÁP CHO VẤN ĐỂ VỀ THỰC PHẨM TRONG DỊCH COVID - 19
}

\author{
Nguyễn Thị Hạnh, Phùng Đức Mạnh, Nguyễn Trúc Thảo My, \\ Nguyễn Mai Linh, Nguyễn Đức Huy
}

Ngày 6 tháng 3 năm 2022

Preprint DOI: osf.io/ghfy5

Tiếp nối phần luận về vấn đề thực phẩm trong mùa dịch giai đoạn 2019 - nưa đầu năm 2021, tại phần luận sau đây, nhóm tiến hành khai thác trong nưa cuối năm 2021.

\section{Các vấn đề về thực phẩm thời điểm hiện tại:}

Sự bùng phát toàn cầu của dịch bệnh COVID-19 đã và đang làm ảnh hưởng nghiêm trọng đến sức khỏe, đời sống, làm gián đoạn các hoạt động trong ngành công nghiệp và thực phẩm trên toàn thế giới. Chính điều này đã khiến lượng cung và cầu trong ngành công nghiệp thực phẩm nói chung trở nên không ổn định trong 2 năm trở lại đây. Một mặt, nhu cầu về mặt hàng này tăng cao do đại dịch, nhưng mặt khác, số lượng người hơn có thể cung cấp nguồn lương thực cần thiết lại đang giảm thiểu đáng kể.

Khi đại dịch tiếp tục lây lan trên khắp thế giới, kèm theo số lượng lây nhiễm gia tăng là các vấn đề về kinh tế, dẫn đến cuộc khủng hoảng lương thực ở nhiều quốc gia bao gồm cả Việt Nam. Tuy nhiên, nửa cuối năm 2021 ghi nhận, dưới tác động của làn sóng dịch COVID-19 lần thứ tư, các doanh nghiệp và người tiêu dùng dần thích nghi với cách sống và tiêu dùng mới, từ đó tránh được tình trạng do lo sợ dịch bệnh làm khan hiếm hàng hóa, mà mua tích trữ các đồ dùng, thực phẩm, sau là tình trạng lợi dụng sự hoang mang của người dân mà đẩy cao giá trị của hàng hóa thiết yếu. Sự bình thường hóa này đã cải thiện, khắc phục được những biến động trong mối quan hệ giữa cung và cầu của ngành thực phẩm vào năm 2020 . Hiện nay, nhu cầu về lương thực của người dân Việt Nam đang có xu hướng gia tăng. Trong khi đó, chuỗi cung ứng lương thực được nhận xét là ổn định, có thể đáp ứng tốt nhu cầu của người dân, không còn hiện tượng giá tăng đột biến gây bất ổn thị trường. Theo Bộ Nông nghiệp và Phát triển nông thôn, khi xã hội trở lại trạng thái bình thường mới, chợ truyền thống và các kênh tiêu thụ, đại lý được mở cửa, dự báo các hoạt động sản xuất và nhu cầu về thực phẩm sẽ ổn định trở lại.

\section{Vấn đề về cầu}

Dịch Covid-19 tái bùng phát vào cuối tháng 4 năm 2021 đã ảnh hưởng không nhỏ tới đời sống của nhân dân. Những hệ lụy của đại dịch là không ít, không thể không nhắc tới tình trạng thất nghiệp, giảm thu nhập hay thay đổi xu hướng chi tiêu của người dân Việt Nam. Từ nửa cuối năm 
2020 cho tới nay, không ít doanh nghiệp đã phá sản, gián tiếp gây ra tình trạng hạn chế về kinh tế của người tiêu dùng. Với những "kinh nghiệm" đã rút ra từ 3 lần cách ly xã hội trước đây, người tiêu dùng Việt Nam đã ý thức được mức độ nghiêm trọng của vấn đề và buộc phải cắt giảm chi tiêu. Có thể thấy rõ ràng là mặt hàng chính được tiêu thụ chỉ còn xoay quanh thực phẩm, đồ dùng thiết yếu và vật tư $\mathrm{y}$ tế. Nhu cầu về thực phẩm tăng cao khiến ngành công nghiệp sản xuất lương thực trở thành một trong những ngành quan trọng nhất thời điểm hiện tại.

Một trong những vấn đề tương đối nan giải nữa đối với người tiêu dùng hiện nay là tại một số tỉnh thành, việc phân phối các mặt hàng, sản phẩm, đặc biệt là lương thực, thực phẩm đang gặp phải nhiều khó khăn khi thực hiện giãn cách xã hội. Các chợ truyền thống, cơ sở giết mổ sẽ bất chợt bị tạm ngưng hoạt động nếu phát hiện ca nhiễm mới tại khu vực lân cận, gây ảnh hưởng lớn đến tiêu thụ và phân phối nguồn thịt trên địa bàn cả nước. Bên cạnh đó nguồn tiêu thụ chính của thực phẩm hiện nay là tại các chợ truyền thống, trong khi nguy cơ bùng phát dịch bệnh tại các chợ là rất cao, với điển hình là lần phong tỏa vào ngày 21/07/2021 tại chợ tạm Trại Găng (quận Hai Bà Trưng, Hà Nội), khiến khoảng 1.000 cư dân ở phường Thành Nhàn phải thực hiện cách ly tại nhà.

Để khắc phục tình trạng này, Nhà nước liên tục khuyến khích người dân mua sắm tại các cửa hàng tiện lợi hay siêu thị lớn như BigC, VinMart hay BRG Mart tại khu vực sinh sống kết hợp với khai báo $\mathrm{y}$ tế nhằm dễ dàng quản lý lịch trình di chuyển của người tiêu dùng trong thời kỳ dịch bệnh. Đồng thời hoạt động của các sàn thương mại điện tử và các phần mềm giao thực phẩm trực tuyến được thúc đẩy mạnh mẽ. Tuy nhiên, những hình thức mua sắm này chỉ phù hợp với một bộ phận người tiêu dùng nhất định. Không thể phủ nhận rằng người tiêu dùng tìm đển những chợ truyền thống hay "chợ cóc" bởi chính sự tiện lợi, giá thành rẻ và tiết kiệm kiệm thời gian của nó. Ngoài ra, những người lớn tuổi dĩ nhiên cũng gặp rất nhiều khó khăn với việc tiếp cận với phong cách "đi chợ trực tuyến" mới này. Cho tới tháng 8/2021 tại Hà Nội và tháng 10/2021 tại Thành phố Hồ Chí Minh, một số chợ truyền thống mới được mở cửa trở lại. Theo ghi nhận, hàng hóa, đặc biệt là các loại hàng thực phẩm, rất phong phú và giá cả một số mặt hàng bắt đầu tiệm cận với mức giá trước dịch bệnh. Đây cũng là tín hiệu đáng mừng cho người tiêu thụ, đặc biệt là sau một thời gian dài thực hiện giãn cách xã hội nghiêm ngặt. Tuy nhiên, người dân vẫn phải nâng cao cảnh giác và luôn phải chuẩn bị sẵn tinh thần nếu các chợ truyền thống tiếp tục bị ngưng hoạt động một cách bất ngờ.

\section{Vấn đề về cung}

Trước tình hình hết sức phức tạp của đại dịch COVID-19 kéo dài, Đảng và Nhà nước đã đưa ra những biện pháp kịp thời nhằm chinh phục được "mục tiêu kép": không chỉ tích cực ngăn chặn dịch bệnh mà còn thúc đầy hoạt động phát triển kinh tế - xã hội. Đảm bảo được cả an sinh xã hội lẫn duy trì chuỗi cung ứng hàng hóa, nguyên liệu sản xuất, giúp các doanh nghiệp có thể "bám trụ"" lại, đặc biệt đối với các mặt hàng lương thực, thực phẩm. Một mục tiêu rõ ràng được đặt ra là sớm đưa đất nước về tình trạng bình thường mới. Đặc biệt trong thời điểm cuối năm 2021 cho tới Tết Nguyên Đán năm 2022, nhu cầu mua sắm nói riêng hay chi tiêu nói chung của người dân trên các tỉnh thành tại Việt Nam được dự báo tất yếu sẽ gia tăng.

Sớm lường trước được tình hình tăng trưởng trong nhu cầu mua sắm, đặc biệt là với mặt hàng lương thực, thực phẩm, các doanh nghiệp đã chủ động trong việc chuẩn bị đầu vào của nguồn hàng hóa, khâu sản xuất và cách thức tiếp cận với người tiêu dùng. Tuy nhiên, một trong những trở ngại

lớn mà các doanh nghiệp phải đối mặt đó chính là là vấn đề về giá cả. Đại dịch COVID-19 diền 
biến phức tạp, công tác phòng, chống dịch được thắt chặt, trực tiếp ảnh hưởng tới một số lĩnh vực trong đó có việc vận chuyển hàng hóa. Việc xây dựng những lộ trình để chủ động với những tuyến vận chuyển đường dài trở nên khó khăn khi các tỉnh thành cách ly độc lập, các đơn vị vận chuyển tăng giá gấp đôi, thậm chí gấp ba lần so với trước đây. Chưa kể tới nguồn thực phẩm chế biến, thực phẩm đông lạnh khổng lồ được nhập khẩu từ nước ngoài cũng bị giới hạn. Bước vào thời kỳ đầu của làn sóng COVID lần thứ tư, chỉ số sản xuất của riêng ngành thực phẩm đã giảm $7,8 \%$ so với cùng thời điểm vào năm 2020 (Hiệp, 2021b). Chi phí sản xuất tăng, thiếu hụt nguồn lao động, đã làm cho việc phục hồi của các doanh nghiệp cũng trắc trở hơn. Đặt ra tiêu chí là bình ổn giá, duy trì mức giá phù hợp, tiệm cận với giá trị các mặt hàng thực phẩm trước khi đại dịch diễn ra nhằm chia sẻ khó khăn với người tiêu dùng, nhưng với việc giá cả tăng cao trong mọi khâu sản xuất, mặt hàng các doanh nghiệp đưa ra thị trường khó có thể giữ nguyên giá trị trước đại dịch. Ghi nhận tại các chợ truyền thống và siêu thị vào cuối tháng $11 / 2021$, giá cả các mặt hàng thực phẩm tươi thiết yếu như thịt, rau, cá tươi thường tăng $20 \%$ đến $25 \%$, và từ $10 \%$ đối với những mặt hàng thực phẩm khác.

Mặc dù, thực tế tình hình dịch bệnh khó khăn, giá cả nguyên liệu sản xuất tăng cao, chi tiêu của người tiêu dùng lại có xu hướng giảm (La et al., 2020), nhưng kể từ đầu tháng 10/2021, Thành phố Hồ Chí Minh bắt đầu triển khai nới lỏng các hoạt động phòng, chống dịch, hoạt động sản xuất cũng từng bước được phục hồi. Trong đó, nhóm ngành hàng lương thực, thực phẩm cũng tăng trưởng mạnh do là nhóm hàng thiết yếu với $8,6 \%$ tăng trưởng so với cùng kỳ năm 2020 . Nhìn chung tại các địa phương, các kênh phân phối vẫn diễn ra bình thường nhằm đáp ứng được nhu cầu mua sắm mặt hàng lương thực của người tiêu dùng đặc biệt là ở thời điểm hiện tại kéo dài tới Tết Nguyên Đán 2022, khi mặt hàng thực phẩm là nhu cầu được đặt lên hàng đầu. Các siêu thị, cửa hàng bán lẻ, cửa hàng tiện lợi mở cửa với nguồn hàng phong phú, dồi dào, đã chuẩn bị đầy các đủ mặt hàng lên kệ trong những ngày cuối năm, duy trì được nguồn cung ứng ổn định tới người tiêu dùng Việt Nam. Bên cạnh đó, các doanh nghiệp nhỏ lẻ tại các địa phương cũng được khuyến khích chuẩn bị sẵn nguồn hàng dự trữ nhất định đảm bảo nguồn hàng sẵn sàng phục vụ nhân dân.

Từ khi bắt đầu đợt dịch thứ 4 đến nay, dựa trên cơ sở kiến nghị của Bộ Công Thương, Chính phủ đã ban hành Công văn số 5187/VPCP-CN ngày 29/7/2021 về việc tạo điều kiện thuận lợi cho việc vận chuyển hàng hóa trong tình hình dịch COVID-19 (BBT, 2021). Chính phủ cũng ghi nhận, đánh giá cao sự chung sức, tham gia tích cực, trách nhiệm trong việc khôi phục nền kinh tế - xã hội của các doanh nghiệp sản xuất, kinh doanh mặt hàng lương thực, thực phẩm. Tháo gỡ những khó khăn cho nhiều doanh nghiệp sản xuất, kinh doanh các mặt hàng thiết yếu, hỗ trợ xúc tiến thương mại, đẩy mạnh kết nối cung - cầu nhằm đáp ứng đủ nhu cầu của nhân dân trong những ngày cuối năm. 


\section{TỔNG KẾT}

Trong tình hình dịch bệnh vừa qua, vấn đề cung cầu thực phẩm là một vấn đề nóng bỏng, mang tính bức thiết. Dịch bệnh hoành hành phần nào khiến cung, cầu thực phẩm trở nên khó khăn hơn bao giờ hết. Từ khi mới bùng dịch và dịch lên tới đỉnh điểm, có khá nhiều địa phương xảy ra tình trạng thiếu hụt lương thực, thực phẩm do nhu cầu của người dân lớn, một phần cũng do việc tích trữ quá nhiều thực phẩm của một vài bộ phận người dân dẫn đến một số khác không còn thực phẩm để mua. Cùng với đó, ở một số địa phương, do dịch bệnh, các hoạt động buôn bán bị trì trệ, nhiều nơi đóng cửa các chợ khiến cho xảy ra tình trạng một vài thực phẩm không thể tiêu thụ như: thanh long, nhãn, ... Trước tình hình ấy, Chính phủ đã kịp thời can thiệp, trấn an tinh thần người dân trước nỗi lo dịch bệnh để ngăn cản việc tích trữ lương thực, thực phẩm dẫn tới thiếu hụt. Đồng thời cũng có rất nhiều các kế hoạch thu mua, chiến dịch "giải cứu" thực phẩm được tổ chức để giúp đỡ người nông dân gặp khó khăn trong việc tiêu thụ nông phẩm. Để mở rộng "đầu ra" cho nông sản, các địa phương đã vận động, kêu gọi các nguồn lực tại chỗ để hỗ trợ thu mua, tiêu thụ nông sản giúp người dân. Một vài địa phương đã chấp nhận tăng thêm phí vận chuyển để có thể thu mua được nguồn thực phẩm cần thiết cho sản xuât, tiêu dùng ${ }^{[23]}$. Thêm vào đó, việc xuất hiện các trang thương mại điện tử cũng góp phần giúp đáp ứng nhu cầu của người dân và giải quyết vấn đề giao lưu buôn bán trong mùa dịch.

Mặc dù tới thời điểm hiện tại, vấn đề cung, cầu thực phẩm đã được giải quyết phần nào, nhưng vẫn còn một vài điều khó khăn. Vậy nên Chính phủ, các địa phương và người dân vẫn cần phải có những cách giải quyết, xử lý khó khăn ấy.

Về Chính phủ, cần ban hành quyết định tới các cơ quan ban ngành, các địa phương về việc đáp ứng đầy đủ nhu cầu của người dân, không để xảy ra tình trạng thiếu hụt thực phẩm. Đồng thời, chính phủ cũng cần trấn an tinh thần người dân, không để người dân lo sợ về việc không có thực phẩm dẫn đến việc tích trữ. Cùng với đó, cần có những giải pháp để giải quyết các nguồn hàng thực phẩm khó tiêu thụ. Cần phải nắm rõ tình hình sản xuất, phân phối, lưu thông hàng hóa để chủ động điều phối hàng hóa, không để xảy ra hiện tượng khan hiếm, thiếu hụt thực phẩm (Hiệp, 2021a).

Các doanh nghiệp trên cả nước cũng cần phải đẩy mạnh sản xuất, chủ động tăng cường nhân sự, liên tục đưa hàng lên kệ, tăng thời gian phục vụ... Cần dự báo nhu cầu tiêu dùng, tham gia trao đổi, làm việc với nhà cung ứng, chủ động nguồn hàng trong trường hợp dịch bệnh diễn biến phức tạp hơn. Quan trọng nhất là cần đẩy mạnh phát triển kênh phân phối thương mại điện tử. (Lý, 2020)

Về phần người dân, thứ nhất, không nên tích trữ lương thực, thực phẩm vì như vậy sẽ gây nên tình trạng một số người không mua được thực phẩm, đồng thời việc dự trữ sẽ gây nên một thực trạng đó là hoang phí, bởi hàng hóa dự trữ không sử dụng nhanh có thể hết hạn sử dụng. Thứ hai, cần phải chung tay, góp sức, tham gia vào các hoạt động, chiến dịch "giải cứu" thực phẩm để có thể giúp đỡ các địa phương khác thoát khỏi khó khăn.

Cung, cầu thực phẩm vốn dĩ đã luôn là một vấn đề quan trọng, trong thời điểm dịch bệnh, nó lại là yếu tố bức thiết hơn cả. Bài tiểu luận này của sinh viên hiện mới chỉ đưa ra phần nào sự bức thiết ấy, và cũng mới chỉ đưa ra một vài đề xuất giải quyết vấn đề ây. Sinh viên mong rằng, một vài những điều ấy cũng có thể góp phần nào cung cấp cho mọi người thông tin về tình hình cung, 
cầu thực phẩm trong mùa dịch này. Đồng thời sinh viên hy vọng những đề xuất mà sinh viên đưa ra cũng sẽ phần nào giải quyết được tình trạng khó khăn trong vấn đề cung cầu thực phẩm mùa dịch.

Tóm lại, để xử lý vấn đề thực phẩm trong mùa dịch, chính phủ cần sử dụng hệ thống xử lý thông tin 3D (Q. H. et al. Vuong, 2022; Q. H. Vuong \& Napier, 2014), tháp văn hóa để đề ra các giải pháp toàn diện căn cơ như xử lý tốt vấn đề thông tin truyền thông, lắng nghe tham vấn chuyên gia, hợp tác các bên liên quan, và xây dựng chính sách, văn hóa minh bạch văn minh đặc biệt là hướng đến đối tượng là doanh nghiệp doanh nhân.

\section{Tài liệu tham khảo:}

BBT. (2021). Kinh nghiệm và giải pháp chống đứt gãy chuỗi cung ứng hàng hóa phục vụ nhu cầu nhân dân trong những đợt giãn cách do đại dịch Covid-19. Bộ Công Thương Việt Nam.

Hiệp, M. (2021a). Tăng cường các giải pháp đảm bảo cung cầu hàng hóa lương thực, thực phẩm thiết yếu trên địa bàn TPHCM. Trang Tin Điện Tử Đảng Bộ Thành Phố Hồ Chí Minh.

Hiệp, M. (2021b). Thay đổi môi trường kinh doanh và giải pháp phục hồi cho doanh nghiệp ngành lương thực, thực phẩm trong bối cảnh mới. Trang Điện Tử Đảng Bộ Thành Phố Hồ Chí Minh.

La, V., Pham, T., Ho, M., Nguyen, M., Nguyen, K.-L. P., Voung, T.-T., Nguyen, T. H.-K., Tran, T., Khuc, V.-Q., Ho, M.-T., \& Vuong, Q.-H. (2020). Policy response, social media and science journalism for the sustainability of the public health system amid COVID-19 outbreak: The Vietnam lessons. Sustainability, 12, 1-35.

Lý, Đ. (2020). Triển khai giải pháp đảm bảo cân đối cung - cầu hàng hóa ứng phó dịch Covid - 19. Trang Tin Điện Tử Đảng Bộ Thành Phố Hồ Chí Minh.

Vuong, Q. H. et al. (2022). Covid-19 vaccines production and societal immunization under the serendipity-mindsponge-3D knowledge management theory and conceptual framework. Humanities and Social Sciences Communications, 9(1), 1-12. https://doi.org/10.1057/s41599-022-01034-6

Vuong, Q. H., \& Napier, N. K. (2014). Making creativity: the value of multiple filters in the innovation process. International Journal of Transitions and Innovation Systems, 3(4). https://doi.org/10.1504/IJTIS.2014.068306 